\title{
Fear of contraceptives' side effects and tensions in marital union among women at risk for unintended pregnancy in southwest Nigeria
}

\author{
Ojo Melvin Agunbiade \& Clementina Oghoadena Osezua
}

\author{
Department of Sociology and Anthropology, Obafemi Awolowo University, \\ Ile-Ife, Nigeria \\ Email: oagunbiade@oauife.edu.ng; \\ ojomelvin@yahoo.com
}

\begin{abstract}
Backgroud: Contraceptive uptake remains low among reproductive age women in Nigeria.This paper explores the views of women at risk for unintended pregnancy concerning contraceptives use, side effects, childrearing burden and the fear of unintended pregnancy in marriage. Methods: We conducted four focus group discussions and 32 in-depth interviews with married women (35-40 years) in two Yoruba communities in Southwest Nigeria.

Results: Contraceptives awareness exists alongside with perceived side effects and misconceptions around contraceptive use among women. Cultural beliefs around the woman's body and disempowerment through unplaned pregnancy before marriage provided limited spaces to negotiate contraceptive use. The impression that contraceptive use among women could promote marital infidelity still holds, while a feeling of husband's extramarital relations was sometimes an opportunity to demand the use of condom.

Conclusion: Contextual understanding of risks of contraceptive use could help in addressing the unmet need for contraceptives among women at risks for an unplanned pregnancy.
\end{abstract}

Keywords: Risk perception, Contraceptive use experiences, Unintended pregnancy, childrearing burden, Southwest Nigeria

\section{Introduction}

Contraceptive use in sub-Saharan Africa remains low despite the increase in the knowledge and awareness of modern contraceptive methods (Alkema, Kantorova, Menozzi, \& Biddlecom, 2013). At the individual level, evidence has implicated real or perceived risk as one amongst other individual factors that are promoting contraceptive discontinuation among women of reproductive age in the region (Bajos et al., 2013; Hindin, McGough, \& Adanu, 2014). There are structural factors that affect contraceptive adoption and dispositions amongst women of reproductive age. Scholars and other stakeholders have called for a more comprehensive understanding of the intersections that exist between individual and structural factors and how these factors affect decisions around contraceptive uptake (May 2016) or switch between methods (Blackstone et al., 2017; Tsui et al., 2017). So far, evidence from this direction and other related studies have found their ways into policy and interventions aimed at promoting the culture of contraceptive uptake in low economies with high fertility rates. However, much progress is still needed as the unmet need for contraceptives in the sub-Sharan Africa remain high among women of reproductive age (Aviisah,
Norman, \& Enuameh, 2017; Wulifan, Brenner, Jahn, \& De Allegri, 2016), including those that are at risks for unplanned pregnancy (Aviisah et al., 2017). The achievements in scaling up contraceptive use in subSaharan Africa, Nigeria inclusive is slow compared to the situation in Asia and (Tsui, Brown, \& Li, 20I7).

A recent systematic review on contraceptive behaviour in the sub-Sharan Africa has shown that the fear of side effects, opposition from husband and husband's fear of infidelity are part of the constraints to contraceptive uptake among women of reproductive age (Wulifan et al., 2016). Misconceptions around the side effects of contraceptive use remain a challenge, especially among childbearing women. The view that every modern contraceptive method has at least a side effects with different outcomes for individual users is connected to dominant fertility values and normative views around sexuality within a given culture (Chebet et al., 20/5). Existing studies on contraceptive behaviour among married women have paid much attention to the existence of misconceptions, but with little regard to the particularity that exists among this social category of women. Married women that are below 30 years of age are in their early reproductive age. Their contraceptive behavior 
and misconceptions around modern contraceptives will differ. The difference might be more evident for women that are above 30 years of age and have some children in their marriages but are aversive to contraceptives. The consequences of having unintended pregnancy separate women in this latter group from those that are in their early reproductive stage and are married. Mumah, Machiyama, Mutua, Kabiru, and Cleland (2015) in a study on contraceptive behaviour of postpartum women (Women at risk of unintended pregnancy) in Kenya revealed that only 49 percent out of the 83 percent that resumed sexual activity after six months had adopted a modern contraceptive method. Also, the study showed that over $40 \%$ of the women discontinued the use of a contraceptive method twelve months after initiation. The discontinuation did not stop their engagement in unprotected sex. The study further revealed that method-related effects and the perceived likelihood of unintended pregnancy influenced this decision. Three months after, four percent had become pregnant (Mumah et al., 20I5).

In Nigeria and many African communities, where patriarchal culture dominates, sexual obligations and child rearing in heterosexual marriages are highly gendered and differentiated (Igenoza, 2003). As such, decisions around the choice of a method reflect cultural beliefs and practices that place a high premium on fertility in marriage (Hindin et al., 2014; Hollos, Larsen, Obono, \& Whitehouse, 2009). Patriarchy, among other structural factors, promotes women's vulnerability in heterosexual relations by encouraging passivity and support for stereotypical attitudes about contraceptive uptake and promotion of women's sexual health (Higgins, Hoffman, \& Dworkin, 2010). This social expectation compromises individual women's agency and subsumes their interests under that of their male partners. The cultural assumption, which is patriarchal, is that women's interests are optimally assured within this arrangement. Nevertheless, the reality is that unintended pregnancy and the burden of childrearing are more on women's sexual and reproductive health in diverse ways (Higgins et al., 2010). Thus, in heterosexual relations, the need for couples to meet these obligations is regularly reinforced in a variety of ways irrespective of the possible implications on their sexual and reproductive health outcomes (Bankole, 1995).

However, at the individual level, there may be variations in cultural norms and values that exert pressure on and shape marital relations (Hindin et al., 2014; Hollos et al., 2009). With the consciousness around the possible implications of low-contraceptive uptake, misconceptions around modern contraceptives and the risk of unintended pregnancy, this research seeks to understand the views and experiences of women at risk of unintended pregnancy and their modern contraceptive uptake exploring perceived or real fear of the side effects of their use as identified by these women. Experiences of women's contraceptive use and non-use can provide valuable insights into haunting fears and unclear notions surrounding modern-day contraceptives. In the present study, we viewed contraceptive risk from the participants' position. Thus, the risk is the individual's subjective judgment about contraceptive use, including the likelihood of adoption and perceived side effects of modern contraceptives. Our research questions were: What is the views of women in the Yoruba community about using modern contraceptive methods? What are the perceived fears and side effects of women who have used at least one modern method? Moreover, in what ways might the burden of childrearing and non-use of modern contraceptive methods create tensions in marital relations. The study took place in two neighbouring Yoruba (Ipetumodu and Moro) communities in Osun State, Nigeria.

\section{Method}

\section{Research design}

Contraceptive use experiences and associated consequences are largely subjective social realities that require exploring the positions and lived experiences of social actors within a cultural setting. As such, we found the qualitative approach suitable. Here we used both focus group discussions (FGD) and in-depth interviews (IDI).

The use of FGD provides opportunities to gain access to group dynamics regarding the fears, perceptions, and relationships influence around contraceptives use among women. The semistructured interviews provided insights into individualized experiences, fears, and tensions that are associated with the perceived risks of contraceptive use. The interviews also helped the participants to speak freely using their own words (Miller \& Glassner, 1997). The average age of first marriage and the average number of births in Nigeria are 18 years and six children (NPC \& ICF, 20I4). Given this context, the chances of having an unintended pregnancy in a marriage per woman increase with age. By 35 years of age, there are possibilities that the average married woman in Nigeria would have had up to six children if there were no fertility problems or post-delivery complications.

Over the years, the burden of childrearing has increased for women with low-socioeconomic 
backgrounds. Partly, the burden has become worse as more married men have lost their source of livelihood, unemployed and coupled with high cost of living in Nigeria. There is also the social expectations around marital norms and responsibilities that preaches subordination and sacrificial living as virtues of motherhood. Within this social framing, married women are expected to satisfy their husbands' sexual needs and care for their children. Performance of these marital roles comes with consequences, which can be satisfying or burdensome. The unreserved expectation to meet the husband's sexual needs in a context of low usage of modern contraceptives could lead to unplanned pregnancy. At age 35 and above, with an average of 4 to 6 children, an additional child that is unintended will increase the childrearing burden as more women are now the breadwinner due to challenging socioeconomic conditions in Nigeria. A recent review has shown an association between the unmet need for contraceptive among women with some children (Wulifan et al., 2016). With the existing low uptake of modern contraceptives in Nigeria and the consequences of meeting up with marital responsibilities, it will be insightful to explore the misconceptions and contraceptive use experiences of married women between 35 and 40 years within a community setting.

\section{Study setting}

The study was conducted in Ipetumodu and Moro. Both communities are in Ife North Local Government Area (LGA) in Osun State Nigeria. The headquarters of the LGA is in Ipetumodu. From historical sources, Ipetumodu and Moro are part of old Yoruba towns that were founded by great Yoruba warriors. Both communities share boundaries with lle-lfe, the cradle of the Yoruba race. There are migrants from other ethnic groups in Nigeria that are residing in these communities. Both towns are largely agrarian with a high proportion of middle-aged men into farming and their female counterparts as petty traders. There is a high presence of young people that are pre-university and college of education students residing in both communities. There is a Federal Government Girls' College, School of Health Technology and other private secondary schools in Ipetumodu. Moro plays host to the Obafemi Awolowo University Distance Learning Centre and Foreign Links-a private College of Education. The fused boundaries between both communities make movement fluid and the choice of residing in either Ipetumodu or Moro a less difficult one for the students in the higher institutions in Moro.

Despite the high proportion of young people and middle-aged people within these communities, sexual and reproductive health care services are mostly absent - just a few maternity homes and a Comprehensive Health Centre that caters for the health needs of all social categories in both communities (Adebayo et al., 20/3). Despite the availability of a primary health centre, the inhabitants including the students have limited access to quality sexual and reproductive health care services. In reality, modern health care services are sourced outside these communities as individuals and social categories have to travel for about 16 kilometers and 38 kilometres to access the overburdened health facilities in Ile-Ife or Osogbo-the capital of Osun State respectively (Adebayo et al., 20l3). The limited access to modern health care facilities is common among most communities in Osun State, especially those that are not in urban areas (Asa, Fatusi, llori, \& Osagbemi, 2015). The limited access to sexual and reproductive health services of both young and middle-aged adults have severe implications for unmet need for contraception in Osun State. As such, there is a need to understand the contraceptive challenges women at risks of unintended pregnancy are exposed to and these sometimes impact on the marital relationships of these women in these communities.

\section{Recruitment and sampling}

Two female community health workers facilitated the initial contacts with the participants. The health workers were briefed on the study objectives and the inclusion criteria, which made it possible to gain their confidence and involvement in the recruitment process. The health workers passed the word along to other women and encouraged them to participate in the study. Participants have married Yoruba women aged between 35 and 40 years, who were living with their husband at the time of the research. Also, they had at least three living children and had a self-reported use of at least one modern contraceptive method in the last six months. All the participants were recruited from the two neighbouring Yoruba communities (Ipetu-Modu and Moro).

A one-page questionnaire was administered to determine participants' eligibility for the FGDs. The questionnaire captured socio-demographic information of the participants.focus was on their age at last birthday, age at marriage, and age at first pregnancy. Additional information included whether the last pregnancy was intended, the number of children ever born and those that are alive among their alive. It was also needful to capture the desired number of children, husband's age, awareness of and use of contraceptives A snowballing technique was adopted as the field assistants moved from one household to another across the core residential 
areas in both communities. The process was fruitful as two female community leaders from each of the communities assisted in facilitating rapport and voluntary recruitment. All the FGD were recruited through this process. Participants that volunteered personal experiences around contraceptive use were approached for a semi-structured face-to-face interview. Other interviewees were recruited through snowball as we had to rely on the participants to refer us to someone within their age group and have had an experience with modern contraceptives. The one-page questionnaire was also applied to ensure the selection of participants based on the inclusion criteria for this study.

The FGD sessions were held first, transcribed, translated and analysed before the commencement of the interviews. The interviews were focused on the salient issues that arose during the FGDs and subsequently used the findings from the FGDs sessions to inform the interviews. Four trained and experienced married female postgraduates of the Department of Sociology and Anthropology at Obafemi Awolowo University conducted all the FGDs and the IDIs. The female students were of the Yoruba extraction and in their early 30 and mid-30s. The choice of using female postgraduate students that are married and within the age bracket of the participants was to gain rapport and increase the ease of relating with an interviewer or moderator. The approach was suitable as some men also felt comfortable with female field assistants that approached their wives for voluntary participation.

In total, we conducted four FGDs among married women aged 35 to 40 years. Each FGD consisted of seven to nine women, for a total of 30 participants. Later, 32 participants who met the same eligibility criteria were interviewed face-to-face. Overall, 62 women participated in the present study.

Based on some personal experiences shared during the FGDs, we invited 15 of those women to participate in the face-to-face interviews. Three of the 15 invited participants declined based on their busy schedule and inability to keep up with appointments. The remaining 20 participants in the interviews were recruited in the same way and with the same inclusion criteria from the same two communities as the FGD participants. The interviews explored experiences of contraceptive use, risk perception associated with contraceptive use and how the perceived or experience of the use can intersect with marital tensions. All the FGDs and IDIs were conducted in the Yoruba language at locations preferred by the participants. The most extended FGD session lasted I hour, and the average was 48 minutes; on average, 45 minutes was spent on each interview.

\section{Data analysis}

We transcribed all of the tape-recorded interviews verbatim and analyzed them thematically. After coding, the transcriptions were re-read several times to identify patterns, which were then extracted by paraphrasing common threads or direct quotes (Braun \& Clarke, 2006).

The themes that emerged were linked to form a comprehensive matrix of the collective perspectives of women who were at risk of unintended pregnancy. Specifically, we sought to explore these women's awareness, perceptions, and experiences of modern contraceptives and how these intersect with their marital relations and childrearing responsibilities. Common themes that emerged through this process included a shared understanding among participants about the fear of side effects and the tensions of avoiding unintended pregnancy in a cultural setting where normative expectations dominate marital relations. The themes were organized and structured around the research questions. Direct quotes from the in-depth interviews and FGDs are presented wherever possible as recommended by Bryman (2006). We identified and discussed four interrelated themes under the following subheadings: Unintended Pregnancies and Associated Tensions in Marital Union; Contraceptive awareness and use in Marriage; Contraceptives use experiences and the "Haunting Shadows" of Side Effects, and Childrearing burden and the dilemma to avoid contraceptive use.

\section{Ethical considerations}

Throughout the study, we followed recommended ethical guidelines on qualitative research (Orb, Eisenhauer, \& Wynaden, 200I). We could not obtain a formal ethical clearance at the time of this study as there was no formal ethics committee at the Obafemi Awolowo University. We briefed all the participants on the study objectives and were encouraged to ask questions. Clarifications were provided, and informed consent was sought before commencing the data collection. All the participants were briefed on rights to participate voluntarily or to withdraw participation from the study without any consequences. After this briefing, we obtained written informed consent from 57 participants in both the FGD and IDIs; the remaining five participants provided verbal consents. The anonymity of participants was ensured, and the FGD participants were encouraged to keep all the discussions confidential.

\section{Results}

The average age of the interviewees was 37.3 years, and that of the focus group discussants was 36.4 
years (See Table I for socio-demographic characteristics). Many of the participants reported an average income of 8,000 Naira per month. Forty-nine women were in monogamous marriages, and 13 were in polygamous marriages. Six interviewees had five children at the time of the study; II had three children, and 15 had four children. Sixteen of the 30 FGD participants had five children, nine had four children, and five had three children. The majority (19) Of the FGD participants reported that their first pregnancy was intended. Twenty- three interviewees said theirs was unintended, and 18 of them had married because they were pregnant. In the interviews, some of the narratives revealed how the occurrence of unplanned pregnancy facilitated a quick entrance of some into marriage; for example, three shared personal experiences of how unintended pregnancy paved ways for them to marry their current

Table I: Socio-demographic characteristics of focus group discussants and interviewees

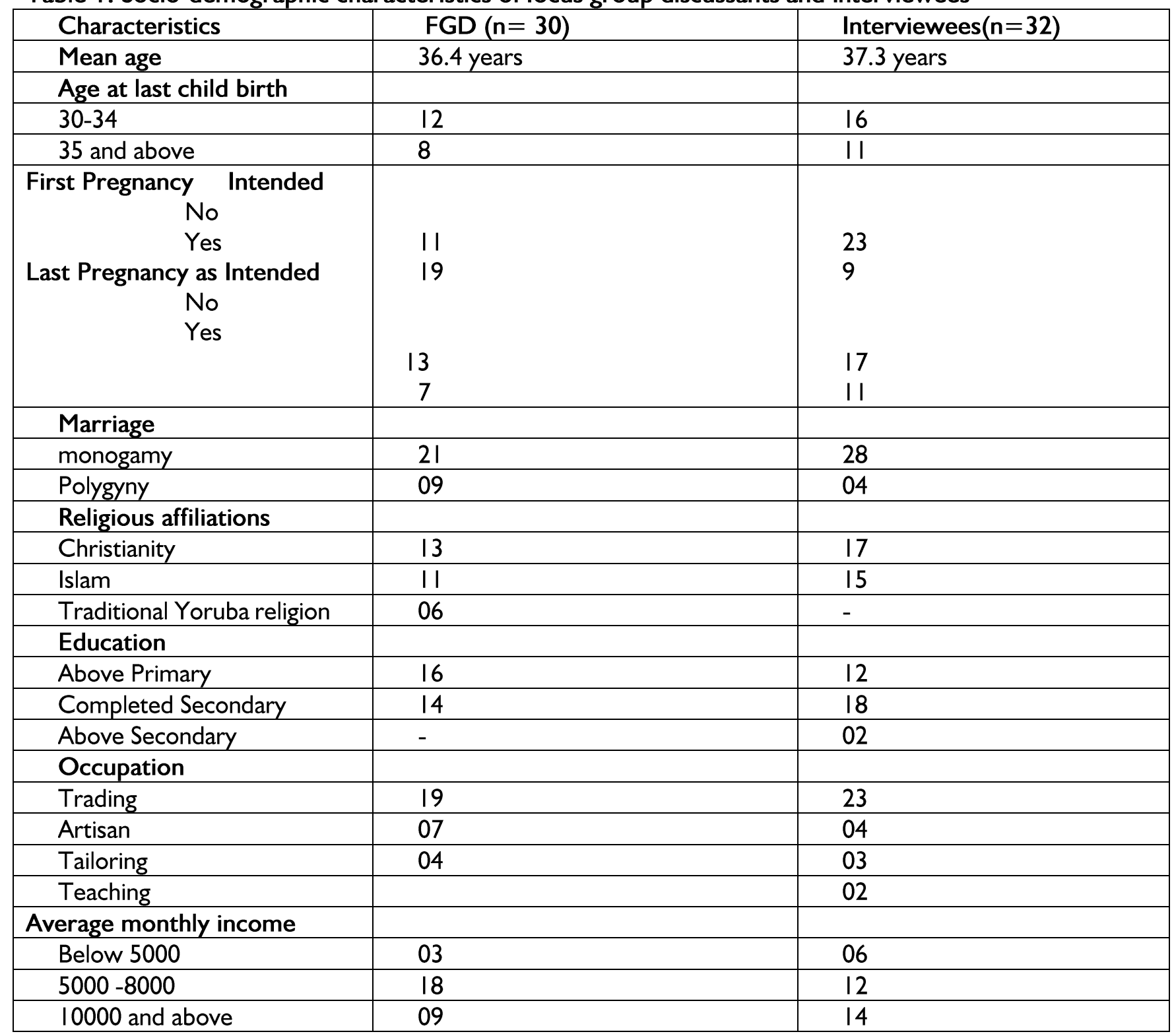

(See Table 2). Two of them described their situation as unfortunate and said they wished they had married a different person from their current husbands. However, the unplanned pregnancy, their religious beliefs, and fear about procurement of induced abortion acted as constraints.
Unintended pregnancies and associated tensions in marital union

The circumstances around the occurrence of first pregnancy could interfere with the quality of communication and conversation around sensitive issues including the use of contraceptives responsibility sharing. Among the participants, the pains and bad feelings that come with having 
unintended pregnancy could linger longer than expected. In their submissions, unintended pregnancy in adolescence or young stage in life could create complications and possible disempowerment for females with such experience. In their view, the quest for social acceptability and conformity to social norms become a priority after a young girl deviates and becomes pregnant unexpected. The circumstances around unplanned pregnancy attract lesser concerns than the social consequences of being a single pregnant mother and having a child without a father. The consciousness around this social intolerance for fertility outside marriage thus gives the males that impregnate a young female undue privilege.

The participants cited the most typical approaches to resolving disputes over the responsibility of unintended pregnancy to include a plea, persuade, and some threats. From their experiences and anecdotal sources, these measures are necessary to ensure acceptance and constant denial of pregnancy responsibility among young males. For them, these measures sometimes could work and result into acceptance of the child and not a marriage between the two. In this direction, some of the participants emphasized that some males would prefer to take the child after delivery and ask the mother to seek for another husband. As recounted by some of the participants, the prevailing political and economic situation in Nigeria has compounded the situation. In one of the interviews, a 37-year-old woman with four children described sexually active young men as those that are more interested in sex and the woman's body than the responsibility that comes with it. The situation has grown worse among adolescents and young people within their communities. More males now impregnate young girls and then leave the responsibilities of caring for the pregnant girl and the baby on their parents or significant others.

At this point, it was necessary to understand further the participants' awareness of contraceptives and their dispositions toward use. A probe into awareness of contraceptives before marriage showed that most participants had a low level of awareness of modern contraceptives as adolescents. This excerpt provides additional insights:

Fifteen years ago, just a few of us were aware of modern contraceptives as adolescents. In those days, it was extremely difficult for boys and girls to talk about using a condom nor a modern contraceptive. One major concern then was how to avoid pregnancy. So, it was possible to hear that lime, dry gin, alligator pepper and a host of other herbs and spirited drinks can be combined to abort unintended pregnancy or avoid pregnancy. Some rascal boys also knew some charms that can be worn during intercourse to avoid unintended pregnancy. During our time many secondary school girls in this community dropped out of school due to unplanned pregnancy. The situation is changing gradually now as more adolescents now know condom and even have access to emergency contraceptives in some medicine stores around (FGD with women Community B)

The excerpt revealed a changing contraceptive behaviour among adolescents. Nonetheless, the participants also shared the view that unintended pregnancy still occurs among young people and adolescents in their communities. The unfortunate trend that has not changed is the denial or rejection of unintended pregnancy among men. For most of the participants, the practice is an age long one but has grown lately among young people in their communities. However, there were occasions when the occurrence of unintended pregnancy becomes a circumstance of entering into marriage. A probe around their views on unplanned pregnancy and marital relations revealed some tensions and bad feelings that are sometimes invoked unconsciously or consciously. Two among the FGD participants shared how their friends, who had entered marriage due to unintended pregnancy, were later regretful and unhappy. For couples who marry in such circumstances, the shadow of unintended pregnancy could hunt them longer than necessary in their marriage:

When you are less prepared for an important event, chances are there that you will be powerless in making the best out of it... It is worse off when a man, you do not love impregnates you. Happiness will be far from such woman, and choice making becomes difficult. (IDI, woman aged 37)

The excerpt portrays powerlessness, displeasure, and frequent, rifts in marriage as developments that could sometimes arise from having a first pregnancy that was unintended. Their context also affects the chances of adopting or suggesting a contraceptive including the use of a condom to their husbands:

Some of us will not discuss any issue relating to contraceptives in the presence or with our husbands. The situation is more challenging for women that have two to three kids and are below 40 years of age. Some women might find it somewhat possible to discuss the use of contraceptive with their husbands when they are 
less financially dependent on their husbands, have more than two children and also the support of one or two family members. (FGD with women Community A)

The consciousness to remain fertile and the normative drive to avoid marital tension with their husbands was dominant across the FGDs and interviews. Such a disposition is normative in a social setting where fertility within marriage is greatly prized, and infertility is stigmatized. This reality perhaps influences the perceived relevance of contraceptive uptake for birth control. The consciousness of the participants towards this paradox also shifted their focus from the prevention of sexual infections through contraceptives to unintended pregnancy.

\section{Contraceptive awareness and use in marriage}

A probe into awareness of contraceptives as married women showed that most were aware. All the participants in both the FGDs and IDls were aware of at least one modern contraceptive method; methods mentioned included condoms, injectables, pills, and the IUD.

Some of us are trying to use one contraceptive method per time. I used IUD for some time but had to remove due to growing side effects such as abdominal pains and massive flows during my menstrual periods. I'm not sure of what next, but I don't want more pregnancies. (IDI with a woman aged 37).

This suggests that many of the participants were aware of the various options available to them with regards to contraceptive use. Furthermore, among the category of women who have used at least a modern contraceptive showed a preference for injectables and pills. As one participant in the FGD said:

We are familiar with the IUD, but it is easier to take an injection or a pill especially when you are doing it without your husband's consent or awareness. It is also quicker and faster to see the results. (A woman aged 39, FGD with women in Community B).

However, previous experiences in and outside marriage were somehow implicated as some of the participants viewed the relevance of and adoption of modern contraceptives from different positions. For instance, a few women in the FGDs argued that despite the irregular request and the fears around suggesting or engaging in a conversation around contraceptive use with a spouse, there were occasions when a woman would have no choice than to place such demands. Knowledge of the husband's extramarital affairs or infidelity could provide a ground for such a request. These women argued that such requests could be made if there had been previous confrontations and confirmed the involvement of husbands in extramarital affairs. Similarly, the participants also opined that women in polygynous marriages who have had their desired number of children might suggest contraception to their husband, especially when conflicts and suspicion are high.

There are times you use a contraceptive without your husbands' knowledge. My husband has other wives, and I have had enough children to cope with. He does not care for us, and I cannot afford any risk of pregnancy. I have some pills that I take. (A woman aged 36, FGD with women in Community A)

However, discussion of the use of female condoms was ignored as some of the participants claimed they have only heard, but not seen nor used one before. Among those who had seen a female condom before, access and lack of interest in its use emerged as dominant constraints. Within this category of women, just two had switched from one method to another based on professional advice from a nurse. Unfortunately, both reported that they had stopped using a modern contraceptive for fear of side effects and some complications that could be traced to contraceptive use.

Contraceptives use experiences and the "haunting shadows" of side effects

A few of the participants claimed to have had unsatisfactory experiences with contraception including their husbands' dissatisfaction with the use of condoms. This metaphor of a "hunting shadow" reiterates the view that contraceptive use and side effects are hardly separable. The mere awareness and the experiences of others about the side effects of contraceptive use created fear and distrust in the minds of some of the participants. Some participants complained that Sony the positive side of Contraceptives emphasized while remaining silent about the side effects. They contested the reasons for the positive angle to the social marketing and expressed displeasure at the deliberate silence concerning possible negative consequences. In the words of another FGD participant:

Modern contraceptives have come to stay, but the side effects hunt and make women afraid. (FGD with women in Community B) 
These excerpts allude to the embodied social fears and disbeliefs in relationships and everyday experiences of some of the participants. One interviewee shared this opinion:

Condoms could have been an alternative, but it has its dangers as well. It breaks and reduces sexual satisfaction most times. (IDI, woman aged 37)

Similarly, another interviewee expounded the view that modern contraceptives use also have some risks that are similar to the non-use of such methods:

...I have used two different contraceptives with different experiences. No method is perfect, but initially, I was very much concerned with the side effects than the benefits. (IDI, woman aged, 35)

These excerpts support the view by some of the participants that there was no such thing as a riskfree contraceptive but were less willing to use contraceptives to manage their fertility. However, others were undecided. There were also some who expressed the view that contraceptives are dangerous and could become a serious problem later in life. Some of the participants based their fears on misinformation they had heard from others. Paradoxically, despite the strong desire to avoid further pregnancies, the majority of the women in the FGDs tended to avoid using contraceptives due to fears about side effects. One woman explained:

In recent times, the dilemma of deciding on pregnancy prevention approach is becoming more complex. At hospitals, we are encouraged to use contraceptives; we want the benefits and not the side effects. It is just like your shadow hunting you at the same time. (FGD with women in Community A)

Across the FGDs, the participants cited both perceived and actual experiences with modern contraceptives as factors that have influenced their decisions about whether to adopt a modern contraceptive method. Among the specific factors, fear as a factor can be found in the following quotes:

I can only attribute it to fear because most of the available methods are less expensive, and some take the usefulness of contraceptives for granted. (IDI, woman aged 35).

Many women believe that the use of contraceptive like IUD often causes excessive blood flow during menstruation. (FGD with women in Community $A$ ).

The negative impressions around contraceptives use among some of the participants could be justified given the limited access to quality sexual and reproductive health care services in their communities. A number of the participants have relied on word of mouth from other women, which could promote suspicion and misinformation about the benefits of using modern contraceptives. Some of the participants explained:

We have to learn from other people's experiences and mistakes. I do not need to experience it first, because the outcomes of life events are less predictable. (IDI, married woman aged 37).

We have heard cases of women who started bleeding more than they did during their menstrual periods because of contraceptive. Nobody will tell you that these contraceptives are perfect, we are only careful with our bodies. (FGD with women in Community B)

Despite the observed barriers to effective uptake, some of the participants still use modern contraceptives. Their attitude towards contraceptive tended to be "no method is risk-free." The risks they mentioned included possible "damage to the womb," "heavy menstrual flow," and "infertility or delay in becoming pregnant." Five of the interviewees who had used at least one form of modern contraceptive described their decisions as risk-taking. Similar attitudes toward contraceptive risk emerged in the focus group discussions based on both personal experiences and those of other women. Some of the women in the FGD narrated stories of others with few personal examples:

I have used Pills and IUD with mixed experiences. I almost aborted the last pregnancy I had because my husband and I have agreed not to give birth again. I visited a private maternity home in a nearby community, but three months later, after I started using another method, I became pregnant, and it almost shattered my marriage. (IDI with a woman aged 36).

In contrast, a participant in one of the FGDs and four other interviewees feared that the use of contraceptive without their husband's knowledge could lead to accusations of promiscuity. Extracts from the FGD and an interview put the above concern in context: 
Let's not deceive ourselves. Many women like me would avoid suggesting the use of condoms just to avoid accusations and counter-accusations. (Woman aged 40, FGD with women in Community B)

I know him well, and I want to avoid all sorts of accusations from him. (IDI, woman aged 35)

The feeling that suggesting a contraceptive use to a partner could raise issues around trust somehow reflects the quality of marital relations among these participants. Beyond their views, cultural stereotypes around the indicators of fidelity or otherwise is a challenge as revealed in the excerpts. Subjective assessment of fidelity in marital relations can pose severe consequences on sustaining contraceptive use among current and perhaps higher risks for potential users. Similarly, there are indications that the fears and misconceptions about contraceptive use spread and discourage potential users from adopting a method. Among the participants, the pace at which mixed experiences with contraceptives is shared appears high. The process is complex and vulnerable to distortion as most participants have depended on hearsay and the experiences of others. Nonetheless, there is mistrusts and fears around uptake and current users.

\section{Childrearing burden and the dilemma to avoid contraceptive use}

With the challenges of childbearing and rearing, some of the participants cited the need to avoid pregnancy and minimize the psychological effects of economic hardships as a rationale for justifying secret use of contraceptives.

Many women are looking for ways to avoid pregnancy because their husbands have left the burden of childcare on their wives alone with the excuse that they don't have money. (FGD with women in Community A)

I hardly yield to sexual demands from my husband after I had my last boy at age 37. I am happy for giving birth to a boy for him after I removed the IUD I was using. Now, I am not sure of which one to use, and I cannot afford to become pregnant again; the burden of caring for five children is too much. (IDI, woman aged 40)

My second child was least expected even though I refused to yield to suggestions from the nurses to adopt a contraceptive method immediately after childbirth. It was difficult to discuss with my husband, and I was afraid of the side effects of contraceptives. Unfortunately, I became pregnant. It was a shame for me then. People started laughing at me even though I was married but got pregnant when I still have an infant. It was very challenging for me, but I have learned my lessons. (IDI, woman aged 36)

The desire to reduce childrearing burden and difficulty making informed decisions on contraceptive uptake further reveal the inherent inequalities and gendered power relations. The sample also included some women who had used or were currently using a modern contraceptive method. Given that majority of the participants have low socio-economic status, it was common to see them emphasising or demonstrating their approval and willingness to conform to the prevailing cultural norms governing marital relations.

Nonetheless, some of the women groaned in the FGDs when discussing the growing challenge of meeting their children's needs with little or no support from their husbands. As narrated by a 40year-old woman:

Some husbands are indifferent to their wives' or children's' well-being. They are just there to have sex with their wives and to avoid unnecessary burden. It is better for women to use contraceptive even without their husband's awareness. (IDI, woman aged 40)

The above extracts further indicate the variations in experiences and challenges women encounter in their households. There are clear indications that women with poor financial incomes and are highly dependent on their husbands will find challenging to engage in open conversation around contraceptive use. Under such circumstances, negotiation is difficult if not impossible, especially for participants who rely on their husbands for their daily expenses and those of their children.

\section{Discussion}

Contraceptive use among women of reproductive age in Nigeria remains low despite the increase in awareness. This research addresses gaps in knowledge by providing context-based information about perceived risks associated with low rates of uptake. It also draws attention to the need to think beyond the simple use of contraceptive methods as a phenomenon unconnected with other issues in marital relations.

The findings demonstrate that a high proportion of women participants are aware of different contraceptives, yet they share deep reservations about the side effects and risks associated with 
modern contraceptives. In part, the low socioeconomic status of the women remains critical to their degree of exposure to adequate information and the ability to make informed decisions. This also reflected on their perceived inabilities to handle the possible side effects of contraceptives. Beyond the low socioeconomic status, inadequate information and ineffective switch between methods among current users of contraceptives could also be a reflection of an inadequate response from the modern healthcare system in Nigeria. As an alternative, several women turned to hearsay and other women's account of contraceptive side effects. The cumulative implications include misinformation and fears about the possible effects of contraceptive use among current and potential users. These findings are similar to a qualitative study on the perceptions and use of contraceptives among women of reproductive age in Ghana (Hindin et al., 20I4).

In the present study, participants who reported current or previous use of contraceptives also described their actions as a risk-taking venture, and others viewed contraceptive use as damaging to a woman's reproductive organs. For instance, some of the women believed that contraceptives could delay fertility and produce inconsistencies in menstrual flow. All of these beliefs undermined contraceptive uptake and responsive switch between among the few users. The misconceptions expressed in our study are also similar to Hindin et al. (20I4) findings among reproductive-age women in Ghana.

Low use of contraceptives thrives within cultural and traditional values that support high fertility within marriage. This finding affirms earlier studies on how a cultural premium on fertility within marriage and the fear that contraceptive use could cause infertility to restrain active adoption and responsive switch of contraceptive methods (Bankole, 1995; Mandara, 2012). In some African communities, children are perceived as a show of wealth and a storehouse of value in the future for their parents (Bankole, 1995; Bongaarts \& Casterline, 2013). Similarly, some of the participants also expressed mixed feelings and dispositions toward condom use as a preventive option against unintended pregnancy. Such feelings are reflecting individual and community stereotypes and misconceptions around contraceptives, which exist in diverse social settings in Africa (Gueye, Speizer, Corroon, \& Okigbo, 2015).

Although the women acknowledged the relevance of condom use in the prevention of sexually transmitted infections, their use was unattractive as the majority of the participants thought that condoms reduce sexual pleasures and satisfaction for both men and women. However, some of the women in the FGDs argued that on a few occasions a woman might encourage their husband to use a condom under two conditions. First, if there was an impression of husband's unfaithfulness to them and they lacked the powers to reject husband's sexual demands. It becomes impressionable to suggest to such husbands to always use a condom with their sexual partners to avoid infecting their wives at home. Similarly, in polygynous marriages, a woman can request their husbands to use a condom. The participants cited the number of living children a woman has and financial independence as additional conditions.

In contrast, discussion of the use of female condoms was ignored as some of the participants claimed they have only heard, but not seen nor used one before. Among those who had seen a female condom before, access and lack of interest in its use emerged as dominant constraints. Nevertheless, the widespread fears, low adoption, and the ineffective switch between contraceptive methods portray gaps between the supply and demand ends of family planning initiatives in Nigeria. Although there are policies in place to increase the uptake of contraceptives, inadequate attention to addressing issues associated with perceived risks of contraceptive use still prevail (Ezeh, Bongaarts, \& Mberu, 20I2).

The gendered power relations in heterosexual marriages worsen the quality of marital relations among women who entered into marriage due to unplanned pregnancy. As revealed in the present study, the timing and intentionality of the first pregnancy affect the quality of marital relations especially in the possibility and expression of sexual rights in heterosexual relations. This finding further points to the insufficiency of unintended pregnancy as a core determinant of quality marital relations. Other factors exist and are essential. These include free and open communication, educational status, and the economic freedom of women in particular.

In the present study, a number of participants with more than two children confirmed the increasing burden of sharing household responsibilities with their husbands. These women have to fend for their children's education and daily upkeep. This reduces the desire for high fertility and more children. These women described their involvement in breadwinning responsibility as an increasing phenomenon among their peers. This finding supports existing literature that women's involvement in breadwinning and their contribution to household expenses have increased in different African settings increased (Eboiyehi, Muoghalu, \& Bankole, 2016; Kwami, 2016; Parry \& Segalo, 2017). In this study, the participants described the functionality of their breadwinning roles as essential to maintaining peaceful marital relations and 
avoidance of constant tensions. The payment of children's school fees, household needs, and the high cost of living were cited as familiar tension-laden issues among couples.

In Nigeria, funding of public schools at the primary and secondary levels is inadequate; this situation is compounded through incessant industrial strikes and disruptions in the academic calendar. This among other factors has stimulated the growth of private schools, which are expensive, and beyond the reach of average Nigerians. Despite these shortcomings, a high proportion of the women felt comfortable with private schools and thus in search of ways to reduce the burden of having another child.

Appropriate and convenient use of contraceptives is essential to reducing the burden of childrearing as shown in the narratives of breadwinning and caring among the participants in this study. Unfortunately, the fears of the majority of the participants emerged from insinuations and experiences of others rather than through personal experience. This misconception may also be associated with cultural beliefs about fertility and perceived risks of contraceptives in and outside marriage. Unwillingness to give some of the available contraceptives a trial might be connected to the belief that contraceptive use could cause either primary or secondary infertility in marriage. As such, the uptake and use of contraceptives are low among the participants in this study. This finding is similar to the existing literature on the usage of contraceptives despite women' awareness of the benefits in developing countries (Gueye et al., 2015; Sedgh \& Hussain, 2014).

Evidence shows quite a many unintended pregnancy are preventable through the effective use and appropriate method switching. Where there is inadequate responsiveness to method-related discontinuation, unintended pregnancies, and unsafe abortions might become rampant (Baird et al., 20I2; Calvert et al., 2013). Inappropriate use, indifference or biased disposition, and incorrect information possessed by nonusers coupled with the spread of negative experiences by some users with methodrelated problems may also deter potential users from adopting other methods. As a relatively heterogeneous group, women at risk for unintended pregnancy could meet at different places such as the market, religious settings, or workplaces to compare their experiences with contraceptives. Through peer interactions like this, users and non-users may share information that could influence or inhibit the use of contraceptives and obstruct the flow of adequate information from health caregivers that could improve the effective use of modern contraceptives.

The media play a significant role in educating women about HIV and other STIs, and thereby promote safer sex. In Nigeria, findings from a recent study of existing edutainment programs that educate women about the benefits of using contraceptives show the need for more culturally sensitive and context-specific issues that cut across broader audiences (Obono, 20l I). The existing programmes could incorporate the likely side effects familiar with some contraceptive methods and how these could be handled appropriately without causing much harm. Similarly, such programs would also be useful in educating women and men about the usefulness of taking proactive steps toward managing sexual and reproductive health through appropriate adoption of contraceptives. In the short run, cultural criticisms and opposition may linger. However, sustained efforts in educating both women and men could be useful in creating more awareness of HIV/STIs and help to reduce the stigma attached to contraceptive use.

In hegemonic patriarchal societies, men are seen as the sole initiator of sexual advances and their wives are seen as submissive to the men's every sexual desire. Within this context, cultural practices and beliefs that promote fertility and procreation remain sacrosanct and could endanger the sexual and reproductive health of women. Asymmetrical power relations continue to characterize conversations around contraceptive use and sexual responsibilities of married women in patriarchal settings (Tenkorang, 20I2). These power relations are further confounded when women are in competitive relationships with other women, such as in polygynous marriages (Bove \& Valeggia, 2009). In the present study, a number of the women reported difficulties in suggesting or negotiating the use of condoms with their husbands. Among the women in our study, the boldness to suggest condom use to one's husband depended on factors such as suspected or actual infidelity of their husbands, a woman's financial condition and the number of living children to a woman. These developments are somehow intersecting with the occurrence of marital relations as the fears and misconceptions around contraceptive use remain.

\section{Limitations of the study}

Despite the rich findings from this study, there are a series of limitations. These include the context specificity of the findings as well as the limitations that may be associated with the research design. The study participants were drawn from a low socioeconomic stratum that is socially disadvantaged based on their limited educational attainment. Thus, we did not capture the experiences of Yoruba women with high educational attainment who are engaged in white-collar jobs and are professionals which may affect their negotiating ability in marriage within the 
context of sexual relationships. Moreover, only two communities in the traditional core of the Yoruba people were explored, which does not take into account the diversity, heterogeneity, and complexities of other Yoruba-speaking people outside the study locations. Finally, the accounts of women could not be corroborated by their husbands who constitute the greater source of fear.

\section{Implications for policy and practice}

The findings point to the need for a contextual understanding of how cultural beliefs and practices shape fertility behaviour and low-utilization of contraceptives among childbearing women. Healthcare providers need to utilize such knowledge and help couples to navigate between cognitive and experiential risks associated with certain contraceptives to making an informed decision on contraceptives uptake. An immediate step in this direction could include post-adoption follow-up from community health workers. The follow-up visit could be in the form of provision of information and assistance for women with contraceptive use complications. The difficulty in engaging in open communication between the women and their husbands shows that more effort is needed to promote men's involvement in contraceptive uptake.

There are indications that more investment in empowerment and retraining of health workers and family planning service providers at the local, state, and national levels could lead to quality counselling of women at risk for unplanned pregnancy as well as address both perceived and real side effects of contraceptive use. In the same vein, there is a need to equip family planning providers at the three tiers of healthcare services in Nigeria with multiple contraceptive options. The availability of different family planning methods will also encourage an effective and timely switch from one method to another in the event of real side effects. In this light, a community- based approach to providing health education to both women and men should become part of the strategies for increasing awareness and debunking misconceptions that hinder the uptake of contraceptives, especially among the socioeconomically disadvantaged populace.

The perceived relevance of having a manageable family size as an imperative for improved quality of life is also emerging at a slow pace. To scale up progress, family planning initiatives must emphasize the innates capabilities of couples to engage in rational decisions about such issues as the spacing of pregnancies. The immediate implication is that it makes room for women to work longer hours and contribute to their household income. Furthermore, community-based organizations could provide useful help in increasing women's knowledge of safer sex and sexual health promotion. Studies have demonstrated the relevance of such organizations. For example, membership and participation in activities of such organizations improved women's knowledge and ability to make informed decisions related to their sexual and reproductive health (Gregson et al., 20ll). Currently, there are such organizations in many communities in Nigeria

\section{Conclusion}

The existence of perceived risks of contraceptive use could create tensions in marital relations in both objective and subjective ways. However, this influence is fluid, and it differs based on individuality and quality of marital relations. Thus, more campaigns and interventions are required to address the perceived and actual fears around contraceptive side effects. Such initiatives will go a long way to assist the category of women at risks of unintended pregnancy to possibly adopt some modern contraceptive methods and to make effective switches from one method to the other in the event of real risks of contraceptive use.

\section{References}

Adebayo, R. A., Balogun, M. O., Adedoyin, R. A., Obashoro-John, O. A., Bisiriyu, L. A., \& Abiodun, O. O. (2013). Prevalence of hypertension in three rural communities of Ife north local Government Area of Osun state, South West Nigeria. International journal of general medicine, 6, 863.

Alkema, L., Kantorova, V., Menozzi, C., \& Biddlecom, A. (20/3). National, regional, and global rates and trends in contraceptive prevalence and unmet need for family planning between 1990 and 2015: a systematic and comprehensive analysis. The Lancet.

Asa, S. S., Fatusi, A., llori, M., \& Osagbemi, K. (20I5). Adequacy of Technical Facilities for Maternal Health Care Delivery in Public Secondary and Tertiary Facilities in Osun State, Nigeria. African Population Studies, 29(2).

Aviisah, M. A., Norman, I. D., \& Enuameh, Y. (20I7). Facilitators and barriers to modern contraception use among reproductive-aged women living in sub-Saharan Africa: a qualitative systematic review protocol. JBI Database of Systematic Reviews and Implementation Reports, 15(9), 2229-2233.

Baird, D., Evers, J., Gemzell-Danielsson, K., Glasier, A., Killick, S., Van Look, P., . . . Cibula, D. (20I2). Family planning 20ll: better use of existing methods, new strategies and more informed choices for female contraception. Human Reproduction Update, I8(6), 670-68I. 
Bajos, N., Teixeira, M., Adjamagbo, A., Ferrand, M., Guillaume, A., \& Rossie, C. (20|3). Normative Tensions and Women's Contraceptive Attitudes and Practices in Four African Countries. Population (English Edition), 68(I), I5-36.

Bankole, A. (1995). Desired fertility and fertility behaviour among the Yoruba of Nigeria: A study of couple preferences and subsequent fertility. Population Studies, 49(2), 317-328.

Bongaarts, J., \& Casterline, J. (20/3). Fertility Transition: Is sub-Saharan Africa Different? Population and development review, 38(s I), 153168.

Bove, R., \& Valeggia, C. (2009). Polygyny and women's health in sub-Saharan Africa. Social $\begin{array}{lll}\text { science \& medicine, 68(I), 21-29. } & \text { 2 }\end{array}$ doi: 10.1016/j.socscimed.2008.09.045

Braun, V., \& Clarke, V. (2006). Using thematic analysis in psychology. Qualitative research in psychology, 3(2), 77-I0I.

Bryman, A. (2006). Integrating quantitative and qualitative research: how is it done? Qualitative research, 6(I), 97-I I3.

Calvert, C., Baisley, K., Doyle, A. M., Maganja, K., Changalucha, J., Watson-Jones, D., . . . Ross, D. A. (2013). Risk factors for unplanned pregnancy among young women in Tanzania. Journal of Family Planning and Reproductive Health Care.

Chebet, J. J., McMahon, S. A., Greenspan, J. A., Mosha, I. H., Callaghan-Koru, J. A., Killewo, J., . . . Winch, P. J. (20I5). "Every method seems to have its problems"-Perspectives on side effects of hormonal contraceptives in Morogoro Region, Tanzania. BMC Women's Health, I5(I), I.

Eboiyehi, F. A., Muoghalu, C. O., \& Bankole, A. O. (2016). In their husbands' shoes: feminism and political economy of women breadwinners in lleIfe, Southwestern Nigeria. Journal of International Women's Studies, 17(4), 102.

Ezeh, A. C., Bongaarts, J., \& Mberu, B. (20I2). Global population trends and policy options. The Lancet.

Gregson, S., Mushati, P., Grusin, H., Nhamo, M., Schumacher, C., Skovdal, M., . . . Campbell, C. (20II). Social capital and women's reduced vulnerability to HIV infection in rural Zimbabwe. Population and development review, 37(2), 333359.

Gueye, A., Speizer, I. S., Corroon, M., \& Okigbo, C. C. (20I5). Belief in family planning myths at the individual and community levels and modern contraceptive use in urban Africa. International perspectives on sexual and reproductive health, $4 I(4), 191$.

Higgins, J. A., Hoffman, S., \& Dworkin, S. L. (20I0). Rethinking gender, heterosexual men, and women's vulnerability to HIV/AIDS. American Journal of Public Health, I00(3), 435.

Hindin, M. J., McGough, L. J., \& Adanu, R. M. (20I4). Misperceptions, misinformation and myths about modern contraceptive use in Ghana. Journal of Family Planning and Reproductive Health Care, 40, 30-35. doi: I 0. I | 36/jfprhc-20 I 2- 100464

Hollos, M., Larsen, U., Obono, O., \& Whitehouse, B. (2009). The problem of infertility in high fertility populations: meanings, consequences and coping mechanisms in two Nigerian communities. Social science \& medicine, 68(I I), 206 I-2068.

Igenoza, A. O. (2003). Polygamy and the African churches : a biblical appraisal of an African marriage system. Ibadan, Nigeria: African Associataion for the Study of Religion.

Kwami, J. D. (20I6). Development From the Margins? Mobile Technologies, Transnational Mobilities, and Livelihood Practices Among Ghanaian Women Traders. Communication, Culture \& Critique, 9(I), I48-I68.

Mandara, M. (20I2). Family planning in Nigeria and prospects for the future. International Journal of Gynecology \& Obstetrics, I I 7(1), I-4.

Miller, J., \& Glassner, B. (1997). The 'inside'and the 'outside': finding realities in interviews. Qualitative research, 99-II 2.

Mumah, J., N.,, Machiyama, K., Mutua, M., Kabiru, C., W.,, \& Cleland, J. (2015). Contraceptive adoption, discontinuation, and switching among postpartum women in Nairobi's urban slums. Studies in family planning, 46(4), 369-386.

NPC , \& ICF. (20|4). Nigeria Demographic and Health Survey 2013. Retrieved from Rockville, Maryland, USA: National Population Commission and ICF International:

Obono, K. (20II). Media Strategies of HIV/AIDS Communication for Behaviour Change in South West Nigeria. Africana (2I55-7829), 5(2).

Orb, A., Eisenhauer, L., \& Wynaden, D. (200I). Ethics in qualitative research. Journal of nursing scholarship, 33(I), 93-96.

Parry, B. R., \& Segalo, P. (2017). Eating Burnt Toast: The Lived Experiences of Female Breadwinners in South Africa. Journal of International Women's Studies, 18(4), 182-196.

Sedgh, G., \& Hussain, R. (20|4). Reasons for contraceptive nonuse among women having unmet need for contraception in developing countries. Studies in Family Planning, 45(2), I5I169.

Tenkorang, E. Y. (20/2). Negotiating safer sex among married women in Ghana. Archives of sexual behavior, 4I(6), I353-I362.

Tsui, A. O., Brown, W., \& Li, Q. (20I7). Contraceptive Practice in sub-Saharan Africa. 
African Population Studies Vol. 32, No. 3, Dec. 2018

Population and development review, n/a-n/a. doi: |0. I I I I/padr.|205 |

Wulifan, J. K., Brenner, S., Jahn, A., \& De Allegri, M. (2016). A scoping review on determinants of unmet need for family planning among women of reproductive age in low- and middle-income countries. BMC Women's Health, I6(I), 2. 